\title{
Study of single nucleotide polymorphisms of $F B W 7$ and its substrate genes revealed a predictive factor for paclitaxel plus cisplatin chemotherapy in Chinese patients with advanced esophageal squamous cell carcinoma
}

\author{
Ying Liu ${ }^{1, *}$, Shu Ning $X u^{1, *}$, Yong Shun Chen ${ }^{2}$, Xiao Yuan Wu ${ }^{1}$, Lei Qiao ${ }^{1}, \mathrm{Ke} \mathrm{Li}^{1}$, \\ Long Yuan ${ }^{3}$ \\ ${ }^{1}$ Department of Medical Oncology of Henan Cancer Hospital, Zhengzhou University Affiliated Cancer Hospital, Zhengzhou, \\ Henan, China \\ ${ }^{2}$ Department of Radiation Oncology of Henan Cancer Hospital, Zhengzhou University Affiliated Cancer Hospital, Zhengzhou, \\ Henan, China \\ ${ }^{3}$ Department of Surgical Oncology of Henan Cancer Hospital, Zhengzhou University Affiliated Cancer Hospital, Zhengzhou, \\ Henan, China \\ *These authors have contributed equally to this work \\ Correspondence to: Ying Liu, email: yaya7207@126.com \\ Keywords: paclitaxel, esophageal squamous cell carcinoma, chemotherapy, single nucleotide polymorphisms, FBW7 \\ Received: December 09, $2015 \quad$ Accepted:May 17, $2016 \quad$ Published: May 31, 2016
}

\section{ABSTRACT}

Paclitaxel plays a major role in the treatment of advanced esophageal squamous cell carcinoma. However, there is no biomarker that could be used to predict the clinical response of paclitaxel. This work was conducted to investigate the association of genetic polymorphisms in FBW7 and its substrate genes and the clinical response of paclitaxel. Patients with advanced esophageal squamous cell carcinoma were treated with paclitaxel $175 \mathrm{mg} / \mathrm{m}^{2}$ over 3 hours day 1 and cisplatin $75 \mathrm{mg} / \mathrm{m}^{2}$ day 1, every 3 weeks. The genotypes of 11 FBW7 and its substrate gene polymorphisms were determined by polymerase chain reaction-restriction fragment length polymorphism (PCR-RFLP) method. Statistical analysis revealed that patients with mTOR rs1057079 AG (OR ${ }_{\text {adjusted }}$ : 4.59; 95\% CI: 1.78-11.86) genotype had significant correlation with the clinical response of paclitaxel when compared with AA genotype after adjustment for sex, age, and chemotherapy cycle. The median progression-free survival (PFS) of patients with advanced ESCC who received paclitaxel plus cisplatin (TP) as first-line treatment is 14.3 months (95\% CI: 9.0-19.60 months). The median PFS (mPFS) of AG genotypes and AA genotypes in mTOR rs1057079 were 17.31 months (95\% CI: 15.918.67 months) and 9.8 months (95\% CI: 8.58-11.02 months) $(p=0.019)$, respectively.

\section{INTRODUCTION}

Esophageal cancer is one of the most common and fatal malignancies in the world [1]. More than twothirds of patients diagnosed with esophageal cancer had unresectable disease. Patients with unresectable or metastatic esophageal cancer have a particularly dismal prognosis, with an overall survival (OS) of 3.0-8.0 months [2]. Esophageal squamous cell carcinoma (ESCC) is the predominant histologic type (90\%-95\%), while the incidence of esophageal adenocarcinoma remains extremely low in China [3]. So far, no standard regimen is recommended for advanced or metastatic ESCC. Taxol, also known as paclitaxel, has been recognized as an antimicrotubule agent that stabilizes microtubule structure within the cells, causing mitotic arrest and apoptosis [4, 5]. Paclitaxel has been used for the treatment of various types of solid cancers, showing response rates in the range of $30-40 \%$ when used alone [6] and $43-56.5 \%$ when used in combination with cisplatin [7, 8] in ESCC. Notably, the clinical responses are entirely different among patients with advanced ESCC, which implicates that individual genetic variation could be a significant factor for drug sensitivity. It has been reported that single nucleotide polymorphisms (SNPs) have association with radiation and chemotherapy dependent pathways. A recent study [9] 
reported that FBW0 7 -null colon cancer cells were more resistant to taxol-induced cell death than the wild type cells. Similar results were also observed in ovarian cancer cell lines with naturally occurring F-box and WD repeat domain-containing 7 (FBW7) mutations [10]. It has been determined that the specific substrates of FBW7 consist of cyclin E [11,12], c-Myc [13,14], c-Jun [15,16], Notch [1618], presenilin [19], Mcl-1 [20], sterol regulatory elementbinding proteins (SREBP) [21,22], mTOR [23], Kruppellike factors (KLFs) [24,25], c-Myb [26], and Aurora A [27]. Proteins encoded by different SNPs of these $F B W 7$ substrate genes are frequently overexpressed in a variety of human cancers. Thus, we detected SNPs of $F B W 7$ and its substrate genes of patients with unresectable or metastatic ESCC who received TP as first-line chemotherapy to investigate the association between the efficacy of TP and the SNPs of $F B W 7$ and its substrate genes and to develop a predictive biomarker for identifying patients that would benefit from paclitaxel therapy.

\section{RESULTS}

\section{Characteristics of the study population}

From January 2012 to January 2015, 134 patients with ESCC met these criteria, and were recruited to receive the study treatment in Henan Cancer Hospital. Among them, 123 patients were evaluated for toxicity and efficacy, which includes 86 men (69.9\%) and 37 women $(30.1 \%)$ with a median age of 62 years (range: 35-75 years). All patients had metastatic disease, which included lymph nodes, mediastinum, lung, liver, adrenal grand, bone and soft tissues. In total, 33 patients $(26.8 \%)$ received esophagectomy; 22 patients $(17.9 \%)$ received radiotherapy. Baseline characteristics are summarized in Table 1. The median total duration of treatment was 4 cycles (2-6 cycles). Among the 123 patients, CR was not observed, 57 patients achieved PR and 39 patients experienced PD. The objective response rate (ORR) and the disease control rate (DCR) of patients with advanced ESCC treated with TP as first-line chemotherapy are $46.3 \%$ and $68.3 \%$, respectively.

\section{Association of $11 \mathrm{FBW} 7$ and its substrate gene polymorphisms with efficacy of paclitaxel}

The genotype distributions of the 11 selected SNPs of $F B W 7$ and its substrate genes and the efficacy of paclitaxel are shown in Table 2. The results of unconditional logistic regression analysis of the genotypes revealed that the patients with $m$ TOR rs $1057079 \mathrm{AG}\left(\mathrm{OR}_{\text {adjusted }}\right.$ : 4.59; 95\% CI: 1.78-11.86) genotype had significant correlation with the clinical response of paclitaxel when compared with AA genotype after adjustment for sex, age, and chemotherapy cycle. However, no significant correlations were observed between the other 10 genotypes examined and the clinical response of paclitaxel.

\section{Association of $11 F B W 7$ and its substrate genes polymorphisms with situation of adverse events}

The genotype distributions of the 11 selected SNPs of $F B W 7$ and its substrate genes and situation of adverse events after paclitaxel plus cisplatin chemotherapy are shown in Table 3 . The results of unconditional logistic regression analysis of the genotypes in $m y b$ rs7435589 revealed that, compared with AA genotype, the individuals with AG genotype (OR adjusted: 2.86; 95\% CI: 1.286.39 ) had significant correlation with the adverse events after adjustment for sex, age, and chemotherapy cycle. Similarly, the genotype distributions of the SNPs results also showed that SNPs rs10521 in NOTCH1 had significant difference. Compared with AA genotype, the individuals with AG (OR adjusted $_{3.23}$; 95\% CI: 1.07-9.69) genotype showed significant correlation with the adverse events after adjustment for sex, age, and chemotherapy cycle. However, no significant differences in other genotypes were observed between the SNPs genetic variants with the adverse events.

\section{Haplotype analysis of $11 F B W 7$ and its substrate gene polymorphisms}

Haplotype analysis was performed with two SNPs (rs210940 and 7435589) across the $m y b$ gene, four SNPs (rs1057079, rs17036508, rs2536 and rs2295080) across the mTOR gene and two SNPs (rs3124591 and rs10521) across the NOTCH1 gene. For each susceptibility analysis of a certain haplotype, all other haplotypes were taken as a reference. As a result, 4 haplotypes were generated after haplotype analysis of the 2 haplotypes across the $m y b$ and NOTCH1 genes respectively; and for $m$ TOR gene, 16 haplotypes were generated. By abnegating those haplotypes with frequency less than $3 \%$, the effective results are shown in Table 4 to Table 6. As shown in Table 5, haplotype of $\mathrm{A}_{\mathrm{rs} 10}$ ${ }_{57079} \mathrm{C}_{\mathrm{rs} 17036508} \mathrm{~T}_{\mathrm{rs} 2536} \mathrm{~T}_{\mathrm{rs} 2295080}$ can increase the risk of an infaust efficacy of paclitaxel [OR $(95 \% C I): 3.16(1.45-6.87)]$. On the contrary, haplotypes of $\mathrm{G}_{\mathrm{rs} 1057079} \mathrm{C}_{\mathrm{rs} 17036508} \mathrm{~T}_{\mathrm{rs} 2536} \mathrm{G}_{\mathrm{rs} 2295080}$ and $\mathrm{A}_{\mathrm{rs} 1057079} \mathrm{C}_{\mathrm{rs} 17036508} \mathrm{~T}_{\mathrm{rs} 2536} \mathrm{~T}_{\mathrm{rs} 2295080}$ can decrease the risk of an infaust efficacy of paclitaxel [OR $(95 \% C I)$ : $0.25(0.07-$ $0.96)$ and $O R(95 \% C I): 0.12(0.02-0.96)]$. At the same time, neither of the haplotypes across the $m y b$ gene nor the NOTCH gene was associated with an increased or decreased infaust efficacy of paclitaxel risk $(p>0.05)$.

\section{Correlation of the curative effect of paclitaxel plus cisplatin chemotherapy with advanced ESCC}

The result of the Kaplan-Meier survival analysis revealed that the median PFS of patients with advanced ESCC who received TP as first-line treatment is 14.3 months (95\% CI: 9.0-19.60 months). The association between the genotype distributions of the 11 selected SNPs of $F B W 7$ and its substrate genes and the PFS was analyzed. The data showed that patients with $m T O R$ 
Table 1: Baseline patient characteristics

\begin{tabular}{|c|c|c|}
\hline \multirow[t]{2}{*}{ Characteristic } & \multicolumn{2}{|c|}{$\begin{array}{c}\text { TP group } \\
\mathrm{N}=123\end{array}$} \\
\hline & No. & $\%$ \\
\hline \multicolumn{3}{|l|}{ Sex } \\
\hline Male & 86 & 69.9 \\
\hline Female & 37 & 30.1 \\
\hline \multicolumn{3}{|l|}{ Age, years } \\
\hline Range & \multicolumn{2}{|c|}{$35-75$} \\
\hline Median & \multicolumn{2}{|c|}{62} \\
\hline \multicolumn{3}{|c|}{ ECOG Performance status } \\
\hline 0 & 78 & 63.4 \\
\hline 1 & 27 & 22.0 \\
\hline 2 & 18 & 14.6 \\
\hline \multicolumn{3}{|l|}{ Metastases } \\
\hline Lymph nodes & 92 & 74.8 \\
\hline Mediastinum & 70 & 56.9 \\
\hline Lung & 38 & 30.1 \\
\hline Liver & 15 & 12.2 \\
\hline Bone & 10 & 8.1 \\
\hline Others & 11 & 8.9 \\
\hline \multicolumn{3}{|l|}{ Esophagectomy } \\
\hline Yes & 33 & 26.8 \\
\hline $\mathrm{NO}$ & 90 & 73.2 \\
\hline \multicolumn{3}{|l|}{ Radiotherapy } \\
\hline Yes & 22 & 17.9 \\
\hline NO & 101 & 82.1 \\
\hline
\end{tabular}

Abbreviations: TP, paclitaxel plus cisplatin; ECOG: Eastern Cooperative Oncology Group

rs 1057079 AG genotype had longer PFS when compared with AA genotype after adjustment for sex, age, and chemotherapy cycle. Only 1 patient was GC genotype in $m$ TOR rs 1057079. The median PFS of AG genotypes and AA genotypes in $m T O R$ rs 1057079 was 17.31 months (95\% CI: $15.9-18.67$ months) and 9.8 months $(95 \% \mathrm{CI}$ : 8.58-11.02 months) ( $p=0.019)$, respectively (Figure 1$)$.

\section{DISCUSSION}

Paclitaxel plays a key role in advanced ESCC firstline chemotherapy. However, its clinical utility is limited by drug resistance, as well as largely varied clinical response. Up to now, there is no biomarker that could be used to predict the clinical efficacy of paclitaxel. Notably, recent studies have demonstrated that FBW7 is involved in the regulation of drug resistance $[10,30]$. FBW7, a wellstudied SCF ubiquitin ligase, is reported to target various oncogenic proteins for ubiquitination [31]. Study has shown that loss of FBW7 leads to an elevated expression of the c-Jun, c-Myc, and Notch-1 oncoproteins, all of which are capable of promoting cell growth [32]. Tumors with mutant FBW7 were more resistant to paclitaxel compared to FBW7 wild-type parental tumors [10]. To our knowledge, this work is the first study to investigate associations between genetic polymorphisms of $F B W 7$ and its substrate genes and the clinical response of paclitaxel.

We detected $M y b$ rs210940, rs7435589, mTOR rs1057079, rs17036508, rs2536, rs2295080, NOTCH rs3124591, rs10521, c-Myc, SREBF2 and FBW7 genotypes. Our results demonstrate that patients with mTOR rs1057079 AG ( $\mathrm{OR}_{\text {adjusted }}: 4.59$; 95\% CI: 1.78 11.86) genotype have significant correlation with the efficacy of paclitaxel when compared with AA genotype after adjustment for sex, age, and chemotherapy cycle. Patients with $m$ TOR rs 1057079 AG genotype experienced an ORR of $47.2 \%$ with the mPFS of 17.3 months ( $95 \% \mathrm{CI}$ : 15.9-18.67 months). However the mPFS of patients with mTOR rs1057079 AA genotype was 9.8 months (8.5811.02 months). No significant correlations were observed between the other 10 genotypes examined and the clinical response of paclitaxel. We further analyzed haplotype gene polymorphisms of mTOR. As a result, haplotype of $\mathrm{A}_{\mathrm{rs} 10570}$ ${ }_{79} \mathrm{C}_{\mathrm{r} 17036508} \mathrm{~T}_{\mathrm{rr2536}} \mathrm{T}_{\mathrm{rs} 2295080}$ can increase the risk of an infaust efficacy of paclitaxel [OR $(95 \% C I): 3.16(1.45-6.87)]$. On the contrary, haplotypes of $\mathrm{G}_{\mathrm{rs} 1057079} \mathrm{C}_{\mathrm{rs} 17036508} \mathrm{~T}_{\mathrm{rs} 2536} \mathrm{G}_{\mathrm{rs} 2225080}$ and $\mathrm{A}_{\mathrm{rs} 1057079} \mathrm{C}_{\mathrm{rs} 17036508} \mathrm{~T}_{\mathrm{rs} 2536} \mathrm{~T}_{\mathrm{rr} 2295080}$ can decrease the risk of an infaust efficacy of paclitaxel [OR $(95 \% C I): 0.25(0.07-$ $0.96)$ and $O R(95 \% C I): 0.12(0.02-0.96)]$. Furthermore, we investigated the association of $F B W 7$ and its substrate gene polymorphisms with situations of adverse events. The data demonstrated that patients with myb rs 7435589 AG genotype and rs10521 AG type in NOTCH1 had high risk of grade 3-4 adverse events after receiving paclitaxel plus cisplatin chemotherapy.

The activation of mTOR is known to positively regulate protein translation and cell proliferation. It has been documented that mTOR plays a critical role not only in cancer angiogenesis, but also in cancer progression [33-34]. Two studies have assessed associations between functional SNPs in mTOR gene and risk of ESCC in Chinese populations. They genotyped several mTOR SNPs in ESCC patients and found a significantly altered risk of ESCC associated with $m$ TOR rs1883965 and $m T O R$ rs2295080 [35-36]. An early study identified seven SNPs of PI3K/PTEN/AKT/mTOR pathway in patients with advanced ESCC treated with 5-Fu, cisplatin or paclitaxel, and explored the association between clinical outcome and genetic variations. Only mTOR FRAP1:rs 11121704 
Table 2: Genotypes of 11 SNPs of $F B W 7$ and its substrate genes and their association with efficacy of paclitaxel

\begin{tabular}{|c|c|c|c|c|c|}
\hline Gene (Genotypes) & $\mathrm{PD}+\mathrm{SD}(\%)$ & PR(\%) & $\chi^{2}$ & $O R(95 \% C I)^{\mathrm{a}}$ & $P^{\mathrm{a}}$ \\
\hline \multicolumn{6}{|l|}{ rs210940(myb) } \\
\hline $\mathrm{CC}$ & $22(36.7)$ & $14(26.4)$ & reference & & \\
\hline CT & $32(53.3)$ & $29(54.7)$ & 2.42 & $2.70(0.70,10.35)$ & 0.15 \\
\hline $\mathrm{TT}$ & $6(10.0)$ & $10(18.9)$ & 0.68 & $1.07(0.42,2.74)$ & 0.88 \\
\hline \multicolumn{6}{|l|}{ rs7435589(myb) } \\
\hline AA & $27(45.0)$ & $22(42.3)$ & reference & & \\
\hline $\mathrm{AG}$ & $28(46.7)$ & $24(46.2)$ & 0.02 & $0.89(0.37,2.12)$ & 0.79 \\
\hline GG & $5(8.3)$ & $6(11.5)$ & 0.33 & $1.36(0.33,5.62)$ & 0.67 \\
\hline \multicolumn{6}{|l|}{ rs $1057079(m T O R)$} \\
\hline AA & $47(77.0)$ & $27(50.9)$ & reference & & \\
\hline $\mathrm{AG}$ & $14(23.0)$ & $25(47.2)$ & 7.58 & $4.59(1.78,11.86)$ & $<0.01$ \\
\hline GG & $0(0.0)$ & $1(1.9)$ & 0.00 & & 1.00 \\
\hline \multicolumn{6}{|l|}{ rs17036508(mTOR) } \\
\hline $\mathrm{TT}$ & $54(90.0)$ & $45(86.5)$ & reference & & \\
\hline $\mathrm{TC}$ & $6(10.0)$ & $7(13.5)$ & 0.32 & $0.89(0.24,3.27)$ & 0.86 \\
\hline \multicolumn{6}{|l|}{$\mathrm{rs} 2536(m T O R)$} \\
\hline $\mathrm{TT}$ & $53(86.9)$ & $46(83.6)$ & reference & & \\
\hline $\mathrm{TC}$ & $7(11.5)$ & $9(16.4)$ & 0.52 & $1.47(0.46,4.74)$ & 0.52 \\
\hline $\mathrm{CC}$ & $1(1.6)$ & $0(0.0)$ & 0.00 & & 1.00 \\
\hline \multicolumn{6}{|l|}{ rs2295080(mTOR) } \\
\hline $\mathrm{TT}$ & $40(76.9)$ & $28(59.6)$ & reference & & \\
\hline TG & $9(17.3)$ & $16(34.0)$ & 3.71 & $2.52(0.88,7.23)$ & 0.08 \\
\hline GG & $3(5.8)$ & $3(6.4)$ & 0.18 & $1.48(0.23,9.73)$ & 0.68 \\
\hline \multicolumn{6}{|c|}{ rs3124591(NOTCH1) } \\
\hline TT & $48(78.7)$ & $43(81.1)$ & reference & & \\
\hline $\mathrm{TC}$ & $7(11.5)$ & $7(13.2)$ & 0.62 & $0.73(0.16,3.26)$ & 0.68 \\
\hline $\mathrm{CC}$ & $6(9.8)$ & $3(5.7)$ & 0.04 & $1.07(0.31,3.72)$ & 0.92 \\
\hline \multicolumn{6}{|l|}{ rs10521(NOTCH1) } \\
\hline AA & $49(80.3)$ & $43(78.2)$ & reference & & \\
\hline $\mathrm{AG}$ & $10(16.4)$ & $11(20.0)$ & 0.20 & $2.25(0.18,27.78)$ & 0.52 \\
\hline GG & $2(3.3)$ & $1(1.8)$ & 0.37 & $4.41(0.29,66.09)$ & 0.28 \\
\hline \multicolumn{6}{|l|}{ rs9642880(c-Myc) } \\
\hline GG & $26(42.6)$ & $30(56.6)$ & reference & & \\
\hline GT & $9(14.8)$ & $8(15.1)$ & 0.22 & $0.99(0.30,3.24)$ & 0.99 \\
\hline $\mathrm{TT}$ & $26(42.6)$ & $15(28.3)$ & 2.72 & $0.48(0.19,1.23)$ & 0.12 \\
\hline \multicolumn{6}{|l|}{ rs9902941(SREBF2) } \\
\hline $\mathrm{CC}$ & $54(88.5)$ & $49(92.5)$ & reference & & \\
\hline CT & $6(9.8)$ & $4(7.5)$ & 0.21 & $0.88(0.18,4.29)$ & (Coptisured) \\
\hline
\end{tabular}




\begin{tabular}{cccccc}
\hline Gene (Genotypes) & PD+SD(\%) & PR(\%) & $\chi^{2}$ & $\boldsymbol{O R}_{(\mathbf{9 5} \% \mathbf{C I})^{\mathbf{a}}}$ & $\boldsymbol{P}^{\mathbf{a}}$ \\
\hline TT & $1(1.6)$ & $0(0.0)$ & 0.00 & & 1.00 \\
rs7685296(FBW7) & & & & \\
CC & $23(37.1)$ & $21(41.2)$ & reference & & \\
CT & $6(9.7)$ & $8(15.7)$ & 0.38 & $1.06(0.28,4.06)$ & 0.93 \\
TT & $33(53.2)$ & $22(43.1)$ & 0.59 & $0.89(0.36,2.22)$ & 0.80 \\
\hline
\end{tabular}

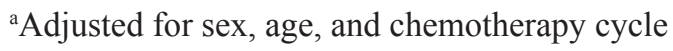

Table 3: Genotypes of 11 SNPs of $F B W 7$ and its substrate genes and their associations with adverse events.

\begin{tabular}{|c|c|c|c|c|c|c|}
\hline Gene (Genotypes) & $0^{b}(\%)$ & $1^{\mathrm{b}}(\%)$ & $2^{b}(\%)$ & $\chi^{2}$ & $O R(95 \% C I)^{\mathrm{a}}$ & $P^{a}$ \\
\hline \multicolumn{7}{|l|}{ rs210940(myb) } \\
\hline $\mathrm{CC}$ & $5(28.6)$ & $14(37.8)$ & $17(27.4)$ & reference & & \\
\hline $\mathrm{CT}$ & $5(35.7)$ & $20(54.1)$ & $36(58.1)$ & 0.64 & $1.40(0.61,3.20)$ & 0.42 \\
\hline $\mathrm{TT}$ & $4(35.7)$ & $3(8.1)$ & $9(14.5)$ & 0.01 & $0.96(0.30,3.09)$ & 0.95 \\
\hline \multicolumn{7}{|l|}{ rs7435589(myb) } \\
\hline AA & $6(42.9)$ & $24(64.9)$ & $19(31.1)$ & reference & & \\
\hline AG & $5(35.7)$ & $11(29.7)$ & $36(59.0)$ & 6.52 & $2.86(1.28,6.39)$ & 0.01 \\
\hline GG & $3(21.4)$ & $2(5.4)$ & $6(9.8)$ & 0.04 & $0.87(0.24,3.12)$ & 0.83 \\
\hline \multicolumn{7}{|l|}{ rs1057079(mTOR) } \\
\hline AA & $11(73.3)$ & $20(54.1)$ & $43(69.4)$ & reference & & \\
\hline $\mathrm{AG}$ & $4(26.7)$ & $17(45.9)$ & $18(29.0)$ & 1.28 & $0.64(0.29,1.39)$ & 0.26 \\
\hline GG & $0(0.0)$ & $0(0.0)$ & $1(1.6)$ & 0.00 & & 1.00 \\
\hline \multicolumn{7}{|l|}{ rs17036508(mTOR) } \\
\hline $\mathrm{TT}$ & $13(86.7)$ & $33(91.7)$ & $53(86.9)$ & reference & & \\
\hline $\mathrm{TC}$ & $6(13.3)$ & $3(8.3)$ & $8(13.1)$ & 0.05 & $1.14(1.14,1.83)$ & 0.83 \\
\hline \multicolumn{7}{|l|}{ rs $2536(m T O R)$} \\
\hline $\mathrm{TT}$ & $14(93.3)$ & $28(73.3)$ & $57(90.5)$ & reference & & \\
\hline $\mathrm{TC}$ & $0(0.0)$ & $10(26.3)$ & $6(9.5)$ & 1.28 & $0.55(0.19,1.55)$ & 0.26 \\
\hline $\mathrm{CC}$ & $1(6.7)$ & $0(0.0)$ & $0(0.0)$ & 0.00 & & 1.00 \\
\hline \multicolumn{7}{|l|}{ rs2295080(mTOR) } \\
\hline $\mathrm{TT}$ & $9(81.8)$ & $24(66.7)$ & $35(67.3)$ & reference & & \\
\hline TG & $1(9.1)$ & $10(27.8)$ & $14(26.9)$ & 0.01 & $0.98(0.38,2.52)$ & 0.97 \\
\hline GG & $1(9.1)$ & $2(5.6)$ & $3(5.8)$ & 0.19 & $0.69(0.14,3.51)$ & 0.66 \\
\hline \multicolumn{7}{|c|}{ rs3124591(NOTCH1) } \\
\hline $\mathrm{TT}$ & $12(75.0)$ & $31(86.1)$ & $48(77.4)$ & reference & & \\
\hline $\mathrm{TC}$ & $2(12.5)$ & $4(11.1)$ & $8(12.9)$ & 0.17 & $1.27(0.41,3.97)$ & 0.68 \\
\hline $\mathrm{CC}$ & $2(12.5)$ & $1(2.8)$ & $6(9.7)$ & 0.14 & $1.30(0.33,5.19)$ & 0.70 \\
\hline
\end{tabular}

(Continued) 


\begin{tabular}{|c|c|c|c|c|c|c|}
\hline Gene (Genotypes) & $0^{b}(\%)$ & $1^{b}(\%)$ & $2^{b}(\%)$ & $\chi^{2}$ & $O R(95 \% C I)^{\mathrm{a}}$ & $P^{a}$ \\
\hline \multicolumn{7}{|l|}{ rs10521(NOTCHI) } \\
\hline AA & $13(86.7)$ & $34(89.5)$ & $45(71.4)$ & reference & & \\
\hline $\mathrm{AG}$ & $2(13.3)$ & $3(7.9)$ & $16(25.4)$ & 4.38 & $3.23(1.07,9.69)$ & 0.04 \\
\hline GG & $0(0.0)$ & $1(2.6)$ & $2(3.2)$ & 0.33 & $2.06(0.17,24.63)$ & 0.57 \\
\hline \multicolumn{7}{|l|}{ rs9642880(c-Myc) } \\
\hline GG & $8(53.3)$ & $20(54.1)$ & $28(45.2)$ & reference & & \\
\hline GT & $1(6.7)$ & $5(13.5)$ & $11(17.7)$ & 1.07 & $1.83(0.58,5.79)$ & 0.30 \\
\hline TT & $6(40.0)$ & $12(32.4)$ & $23(37.1)$ & 0.00 & $0.99(0.44,2.21)$ & 0.92 \\
\hline \multicolumn{7}{|l|}{ rs9902941(SREBF2) } \\
\hline $\mathrm{CC}$ & $14(93.3)$ & $32(86.5)$ & $56(90.3)$ & reference & & \\
\hline $\mathrm{CT}$ & $1(6.7)$ & $3(8.1)$ & $6(9.7)$ & 0.37 & $1.53(0.39,6.03)$ & 0.40 \\
\hline $\mathrm{TT}$ & $0(0.0)$ & $2(5.4)$ & $0(0.0)$ & 1.37 & $0.20(0.01,2.90)$ & 0.24 \\
\hline \multicolumn{7}{|l|}{ rs7685296(FBW7) } \\
\hline $\mathrm{CC}$ & $9(60.0)$ & $16(42.1)$ & $19(31.7)$ & reference & & \\
\hline $\mathrm{CT}$ & $2(13.3)$ & $4(10.5)$ & $8(13.3)$ & 0.68 & $1.66(0.50,5.53)$ & 0.40 \\
\hline TT & $4(26.7)$ & $18(47.4)$ & $33(55.0)$ & 2.80 & $2.01(0.89,4.59)$ & 0.09 \\
\hline
\end{tabular}

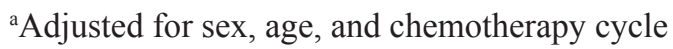

${ }^{b}$ represents the number of adverse events, 0 : no adverse events, 1:1-2 grade adverse events, $2: \geq 3$ grade adverse events

Table 4: Haplotype analysis of the myb gene in subjects

\begin{tabular}{lccccc}
\hline Haplotype & PD+SD (\%) & PR(\%) & $\chi^{2}$ & OR(95\%CI) & $P$ \\
\hline $\mathrm{C}^{1} \mathrm{~A}^{2}$ & $8(6.8)$ & $13(12.7)$ & 2.16 & $0.51(0.20,1.27)$ & 0.14 \\
$\mathrm{C}^{1} \mathrm{G}^{2}$ & $36(29.9)$ & $35(33.5)$ & 0.30 & $0.85(0.48,1.50)$ & 0.58 \\
$\mathrm{~T}^{1} \mathrm{~A}^{2}$ & $74(61.5)$ & $55(52.7)$ & 1.97 & $1.47(0.86,2.52)$ & 0.16 \\
\hline
\end{tabular}

${ }^{1}:$ rs2 10940 site, ${ }^{2}:$ rs7435589 site

Table 5: Haplotype analysis of the $m$ TOR gene in subjects

\begin{tabular}{lccccc}
\hline Haplotype & PD+SD (\%) & PR(\%) & $\chi^{2}$ & OR(95\%CI) & $\boldsymbol{P}$ \\
\hline $\mathrm{A}^{1} \mathrm{C}^{2} \mathrm{~T}^{3} \mathrm{G}^{4}$ & $3(3.0)$ & $3(3.5)$ & 0.06 & $0.82(0.17,4.00)$ & 0.81 \\
$\mathrm{~A}^{1} \mathrm{C}^{2} \mathrm{~T}^{3} \mathrm{~T}^{4}$ & $86(86.0)$ & $63(66.5)$ & 8.89 & $\mathbf{3 . 1 6 ( 1 . 4 5 , 6 . 8 7 )}$ & $<\mathbf{0 . 0 1}$ \\
$\mathrm{G}^{1} \mathrm{C}^{2} \mathrm{C}^{3} \mathrm{G}^{4}$ & $4(4.0)$ & $5(5.4)$ & 0.25 & $0.71(0.18,2.72)$ & 0.62 \\
$\mathrm{G}^{1} \mathrm{C}^{2} \mathrm{~T}^{3} \mathrm{G}^{4}$ & $3(3.0)$ & $10(10.4)$ & 4.61 & $\mathbf{0 . 2 5 ( 0 . 0 7 , 0 . 9 6 )}$ & $\mathbf{0 . 0 3}$ \\
$\mathrm{G}^{1} \mathrm{C}^{2} \mathrm{~T}^{3} \mathrm{~T}^{4}$ & $1(1.0)$ & $7(7.7)$ & 5.60 & $\mathbf{0 . 1 2 ( 0 . 0 2 , 0 . 9 6 )}$ & $\mathbf{0 . 0 2}$ \\
\hline
\end{tabular}

${ }^{1}$ : rs1057079 site, ${ }^{2}$ : rs 17036508 site, ${ }^{3}:$ rs 2536 site, ${ }^{4}:$ rs 2295080 site

homozygosity was associated with a poor response to paclitaxel [37]. Gratifyingly, our work unveiled significant association between genetic variants in $m T O R$ and the clinical response of paclitaxel in patients with ESC, although it is too eary for us to conclude that $m T O R$ rs $1057079 \mathrm{AG}$ is the biomarker of paclitaxel response since the sample sizes of this study is relatively small.

Currently, we are enrolling patients in a large sample size clinical trial to further verify the association between SNPs of $m T O R$ and the response of paclitaxel. The 
Table 6: Haplotype analysis of the NOTCH1 gene in subjects

\begin{tabular}{lcccc}
\hline Haplotype & PD+SD (\%) & PR(\%) & $\chi^{2}$ & OR(95\%CI) \\
\hline $\mathrm{C}^{1} \mathrm{~A}^{2}$ & $90(75.2)$ & $83(78.0)$ & 0.23 & $0.85(0.45,1.63)$ \\
$\mathrm{C}^{1} \mathrm{G}^{2}$ & $11(8.9)$ & $10(9.7)$ & 0.04 & $0.91(0.37,2.24)$ \\
$\mathrm{T}^{1} \mathrm{~A}^{2}$ & $16(13.1)$ & $10(9.7)$ & 0.63 & $1.40(0.61,3.23)$ \\
\hline
\end{tabular}

${ }^{1}:$ rs3124591 site, ${ }^{2}$ : rs 10521 site

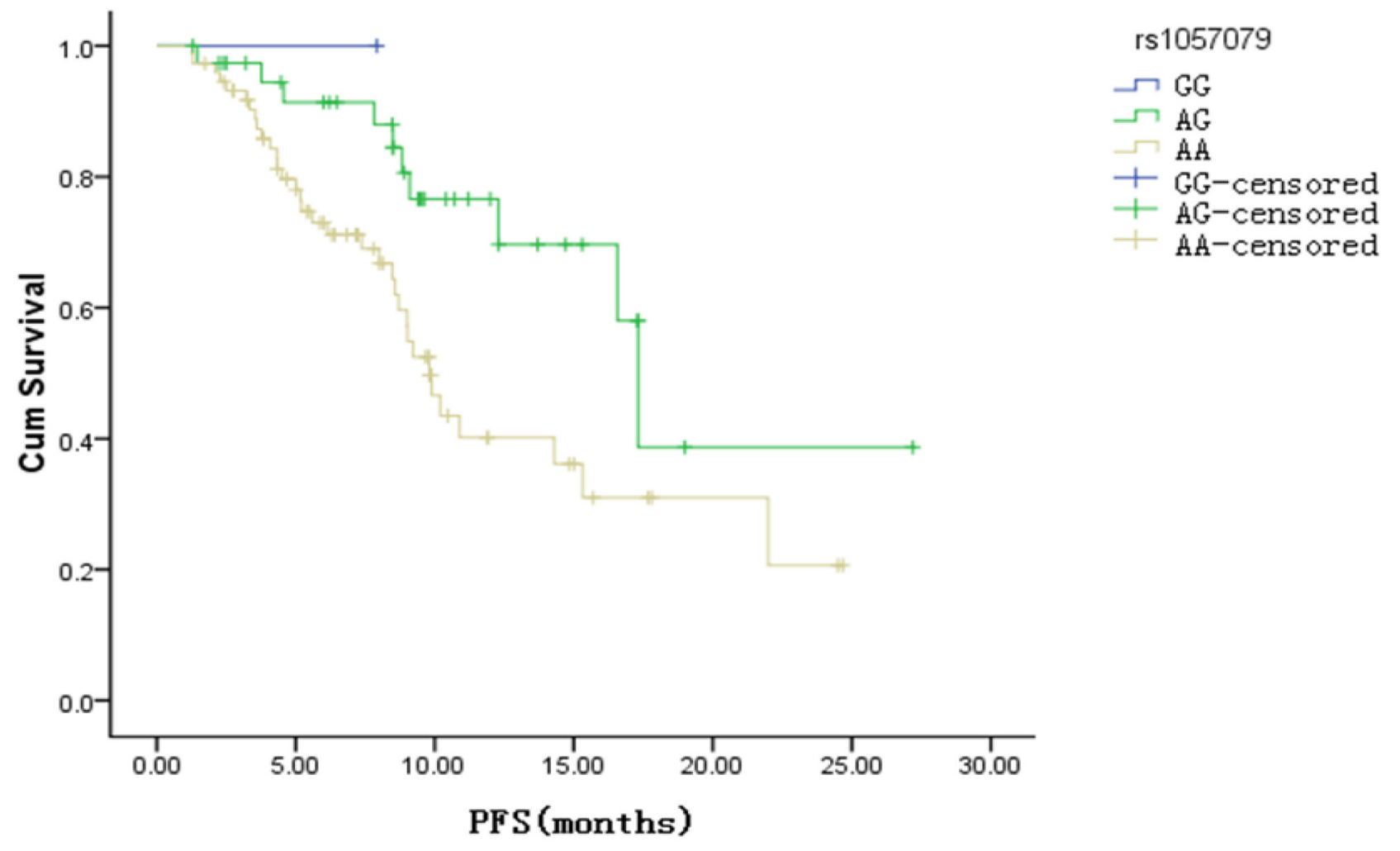

Figure 1: Kaplan Meier survival curve of progression free survival (PFS) about rs1057079 site (p <0.01)

ultimate goal is to allow for the selection of the optimal therapy that would provide the most benefit and least toxicity for patients with ESCC from paclitaxel treatment.

To conclude, in SNPs of FBW7 and its substrate genes, the mTOR rs1057079 AG genotype could be used to predict the clinical response and to achieve better mPFS of patients with advanced ESCC treated with TP regimen as first-line chemotherapy. Further investigation with a larger number of patients study is needed to confirm the predictive values of genetic polymorphisms in mTOR signaling pathways.

\section{MATERIALS AND METHODS}

\section{Patients}

This was a prospective analysis of patients with advanced ESCC who received TP as first line chemotherapy. The study was approved by the Ethics
Committee of Zhengzhou University. Written informed consents for chemotherapy were obtained from all patients. All patients agreed to these studies and the preservation of genomic DNA for future investigations. Patients had to be at least 18 years of age at the time of registration and had histologically or cytologically confirmed ESCC, which was surgically unresectable or recurrent. They also had to have an Eastern Cooperative Oncology Group (ECOG) performance status of 0-2, a life expectancy of $>12$ weeks with sufficient bone marrow, liver, renal and cardiovascular function.

\section{Treatment plan}

Patients were treated with paclitaxel $175 \mathrm{mg} / \mathrm{m}^{2}$ over 3 hours day 1 and cisplatin $75 \mathrm{mg} / \mathrm{m}^{2}$ day 1 , every 3 weeks. Patients receiving paclitaxel were premedicated with $10 \mathrm{mg}$ of oral dexamethasone at 12 and 6 hours before the infusion and with intramuscular injection diphenhydramine and 
intravenous $\mathrm{H} 2$ receptor antagonist within 60 minutes before the infusion of paclitaxel to reduce the risk of hypersensitivity reaction. Cisplatin was administered with hydration and forced diuresis, and patients underwent routine monitoring of electrolytes, serum creatinine, and magnesium. The combination therapy was up to maximum 6 cycles. Treatment was discontinued until the documented disease progression, unacceptable toxicity or patient's refusal.

\section{SNP selection and genotyping}

$M y b$, mTOR, NOTCH, c-Myc, SREBF2 and FBW7 genes were identified based on Chinese population data in HapMap database (http://www.hapmap.org). SNPs in $M y b$, mTOR, NOTCH, $c-M y c$, SREBF2 and FBW7 were selected by bioinformatics data bank using Haploview software, bioinformatics software packages such as TargetScan Human 6.2 (http://www.targetscan.org/), miRanda (http:// microrna.org/) and Patrocles (http://www.patrocles.org/) to offer potential miRNA binding sites within the 3'UTRs of these genes. As a result, totally 11 SNPs in these genes were included for further genotyping with the criteria of a minor allele frequency (MAF) greater than 5\%. Polymerase chain reaction restriction fragment length polymorphism (PCR-RFLP) was used to analyze the polymorphisms of $m T O R$ rs1057079, rs17036508, rs2536, rs2295080, NOTCH rs3124591, rs10521, c-Myc, SREBF2 and FBW7 rs7685296. The digestion products were visualized by electrophoresis on 3\% agarose gel and the genotypes were inferred from the number of bands observed in the gel.

\section{Statistical analysis}

Response was assessed according to the Response Evaluation Criteria in Solid Tumors (RECIST) version 1.0 [28] as complete response (CR), partial response (PR), stable disease $(\mathrm{SD})$ or progressive disease $(\mathrm{PD})$ in patients with measurable lesions. Toxicities were graded according to the National Cancer Institute's Common Terminology Criteria for Adverse Events (CTCAE) version 4.0 [29]. Progression-free survival (PFS) was measured from the initiation of TP to the occurrence of progression, or death without evidence of progression. Follow-up evaluations were performed after every 3 months for 3 years by endoscopy and CT scan. The last follow-up was performed in June 2015.

The SPSS 21.0 statistical software package was used for statistical analyses. Student's t-test for continuous variables and Chi-squared $\left(c^{2}\right)$ test for categorical variables were used to compare the differences in the distributions of major demographic variable, as well as the genotypes of selected SNPs between the ESCC patients. Unconditional logistic regression was applied to estimate the associations between genetic polymorphisms and the risk of ESCC by computing the odds ratios (ORs) and its 95\% confidence intervals (CIs). Online SHEsis (http://analysis.bio-X.cn/ myAnalysis.php) was applied for haplotype prediction and analysis. The Kaplan-Meier method was used to estimate the relationship between PFS and clinical response of paclitaxel; the log-rank test of the null hypothesis of a common survival curve was used to compare survival curves. A P-value of less than 0.05 was considered to be statistically significant and all the inspections were two-side test.

\section{ACKNOWLEDGMENTS}

This work was supported by National Natural Science Foundation of China (grant number 81201954). We thank Dr. Peng Liu for proofreading of the manuscript.

\section{CONFLICTS OF INTEREST}

The authors declare no conflict of interest.

\section{REFERENCES}

1. Jemal A, Siegel R, Ward E, Murray T, Xu J, Smigal C, Thun MJ. Cancer statistics, 2006. CA Cancer J Clin. 2006; 56: $106-130$.

2. Vestermark LW, Sørensen P, Pfeiffer P. Chemotherapy to patients with metastatic carcinoma of the esophagus and gastro-esophageal junction. A survey of a Cochrane review. Ugeskr Laeger. 2008; 170: 633-636.

3. Wang AH, Liu Y, Wang B, He YX, Fang YX, Yan YP. Epidemiological studies of esophageal cancer in the era of genome-wide association studies. World J Gastrointest Pathophysiol. 2014; 5:335-343.

4. Baird RD, Tan DS, Kaye SB. Weekly paclitaxel in the treatment of recurrent ovarian cancer. Nat Rev Clin Oncol. 2010; 7:575-582.

5. Kavallaris M. Microtubules and resistance to tubulinbinding agents. Nat Rev Cancer. 2010; 10:194-204.

6. Ajani JA, Ilson DH, Daugherty K, Pazdur R, Lynch PM, Kelsen DP. Activity of taxol in patients with squamous cell carcinoma and adenocarcinoma of the esophagus. J Natl Cancer Inst. 1994; 86:1086-1091.

7. Polee MB, Eskens FA, van der Burg ME, Splinter TA, Siersema PD, Tilanus HW, JVerweij J, Stoter G, van der Gaast A. Phase II study or bi-weekly administration of paclitaxel and cisplatin in patients with advanced oesophageal cancer. Br J Cancer. 2002; 86:669-673.

8. Huang J, Zhou Y, Zhang H, Qu T, Mao Y, Zhu H, Quan L, Xing P, Wang J, He J, Xu N, Sun Y. A phase II study of biweekly paclitaxel and cisplatin chemotherapy for recurrent or metastatic esophageal squamous cell carcinoma: ERCC1 expression predicts response to chemotherapy. Med Oncol. 2013; 30:343-349.

9. Wu X, Gu J, Wu TT, Swisher SG, Liao Z, Correa AM, Liu J, Etzel CJ, Amos CI, Huang M, Chiang SS, Milas L, Hittelman WN, Ajani JA. Genetic variations in radiation and chemotherapy drug action pathways predict clinical 
outcomes in esophageal cancer. J Clin Oncol. 2006; 24: 3789-3798.

10. Wertz IE, Kusam S, Lam C, Okamoto T, Sandoval W, Anderson DJ, Helgason E, Ernst JA, Eby M, Liu J, Belmont LD, Kaminker JS, O'Rourke KM, et al. Sensitivity to antitubulin chemotherapeutics is regulated by MCL1 and FBW7. Nature. 2011; 471:110-114.

11. Koepp DM, Schaefer LK, Ye X, Keyomarsi K, Chu C, Harper JW, Elledge SJ. Phosphorylation-dependent ubiquitination of cyclin $\mathrm{E}$ by the SCFFbw7 ubiquitin ligase. Science. 2001; 294:173-177.

12. Minella AC, Welcker M, Clurman BE. Ras activity regulates cyclin E degradation by the Fbw7 pathway. Proc Natl Acad Sci USA. 2005; 102:9649-9654.

13. Yada M, Hatakeyama S, Kamura T, Nishiyama M, Tsunematsu R, Imaki H, Ishida N, Okumura F, Nakayama K, Nakayama KI. Phosphorylation-dependent degradation of c-Myc is mediated by the F-box protein Fbw7. EMBO J. 2004; 23:2116-2125.

14. Welcker M, Orian A, Jin J, Grim JE, Harper JW, Eisenman $\mathrm{RN}$, Clurman BE. The Fbw7 tumor suppressor regulates glycogen synthase kinase 3 phosphorylation-dependent c-Myc protein degradation. Proc Natl Acad Sci USA. 2004; 101:9085-9090.

15. Wei W, Jin J, Schlisio S, Harper JW, Kaelin WG Jr. The v-Jun point mutation allows c-Jun to escape GSK3dependent recognition and destruction by the Fbw7 ubiquitin ligase. Cancer Cell. 2005; 8:25-33.

16. Hoeck JD, Jandke A, Blake SM, Nye E, Spencer-Dene B, Brandner S, Behrens A. Fbw7 controls neural stem cell differentiation and progenitor apoptosis via Notch and c-Jun. Nat Neurosci. 2010; 13:1365-1372.

17. Babaei-Jadidi R, Li N, Saadeddin A, Spencer-Dene B, Jandke A, Muhammad B, Ibrahim EE, Muraleedharan R, Abuzinadah M, Davis H, Lewis A, Watson S, Behrens A, Tomlinson I, Nateri AS. FBXW7 influences murine intestinal homeostasis and cancer, targeting Notch, Jun, and DEK for degradation. J Exp Med. 2011; 208:295-312.

18. Tetzlaff MT, Yu W, Li M, Zhang P, Finegold M, Mahon K, Harper JW, Schwartz RJ, Elledge SJ. Defective cardiovascular development and elevated cyclin E and Notch proteins in mice lacking the Fbw7 F-box protein. Proc Natl Acad Sci USA. 2004; 101:3338-3345.

19. Rocher-Ros V, Marco S, Mao JH, Gines S, Metzger D, Chambon P, Balmain A, Saura CA. Presenilin modulates EGFR signaling and cell transformation by regulating the ubiquitin ligase Fbw7. Oncogene. 2010; 29:2950-2961.

20. Inuzuka H, Shaik S, Onoyama I, Gao D, Tseng A, Maser RS, Zhai B, Wan L, Gutierrez A, Lau AW, Xiao Y, Christie AL, Aster J, Settleman J, Gygi SP, Kung AL, Look T, Nakayama KI, DePinho RA, Wei W. $\mathrm{SCF}(\mathrm{FBW7})$ regulates cellular apoptosis by targeting
MCL1 for ubiquitylation and destruction. Nature. 2011; 471:104-109.

21. Sundqvist A, Bengoechea-Alonso MT, Ye X, Lukiyanchuk V, Jin J, Harper JW, Ericsson J. Control of lipid metabolism by phosphorylation-dependent degradation of the SREBP family of transcription factors by $\mathrm{SCF}(\mathrm{Fbw} 7)$. Cell Metab. 2005; 1:379-391.

22. Punga T, Bengoechea-Alonso MT, Ericsson J. Phosphorylation and ubiquitination of the transcription factor sterol regulatory element-binding protein-1 in response to DNA binding. J Biol Chem. 2006; 281:25278-25286.

23. Fu L, Kim YA, Wang X, Wu X, Yue P, Lonial S, Khuri FR, Sun SY. Perifosine inhibits mammalian target of rapamycin signaling through facilitating degradation of major components in the mTOR axis and induces autophagy. Cancer Res. 2009; 69:8967-8976.

24. Liu N, Li H, Li S, Shen M, Xiao N, Chen Y, Wang Y, Wang W, Wang R, Wang Q, Sun J, Wang P. The Fbw7/human CDC4 tumor suppressor targets proproliferative factor KLF5 for ubiquitination and degradation through multiple phosphodegron motifs. J Biol Chem. 2010; 285:18858-18867.

25. Zhao D, Zheng HQ, Zhou Z, Chen C. The Fbw7 tumor suppressor targets KLF5 for ubiquitin mediated degradation and suppresses breast cell proliferation. Cancer Res. 2010; 70:4728-4738.

26. Thompson BJ, Jankovic V, Gao J, Buonamici S, Vest A, Lee JM, Zavadil J, Nimer SD, Aifantis I. Control of hematopoietic stem cell quiescence by the E3 ubiquitin ligase Fbw7. J Exp Med. 2008; 205:1395-1408.

27. Finkin S, Aylon Y, Anzi S, Oren M, Shaulian E. Fbw7 regulates the activity of endoreduplication mediators and the p53 pathway to prevent drug-induced polyploidy. Oncogene. 2008; 27:4411-4421.

28. Therasse P, Arbuck SG, Eisenhauer EA. New guidelines to evaluate the response to treatment in solid tumors: European Organization for Research and Treatment of Cancer, National Cancer Institute of the United States, National Cancer Institute of Canada. J Natl Cancer Inst. 2000; 92: 205- 216.

29. 29. National cancer institute common terminology criteria for adverse events (CTCAE) v.4.0. 2010. Available: http:// evs.nci.nih.gov/ftp1/CTCAE/About.html.

30. Inuzuka H, Fukushima H, Shaik S, Liu P, Lau AW, Wei W. Mcl-1 ubiquitination and destruction. Oncotarget. 2011; 2:239-244. doi: 10.18632/oncotarget.242.

31. Welcker M, Clurman BE. FBW7 ubiquitin ligase: a tumor suppressor at the crossroads of cell division, growth and differentiation. Nat Rev Cancer. 2008; 8:83-93.

32. Minella AC, Clurman BE. Mechanisms of tumor suppression by the SCF(Fbw7). Cell Cycle. 2005; 4:1356-9.

33. Pennathur A, Gibson MK, Jobe BA, Luketich JD. Oesophageal carcinoma. Lancet. 2013; 381:400-412. 
34. Shu J, Huang M, Tian Q, Shui Q, Zhou Y, Chen J. Down regulation of angiogenin inhibits the growth and induces apoptosis in human bladder cancer cells through regulating AKT/mTOR signaling pathway. J Mol Histol. 2015; 46:157-171.

35. Zhu J, Wang M, Zhu M, He J, Wang JC, Jin L, Wang XF, Xiang JQ, Wei Q. Associations of PI3KR1 and mTOR polymorphisms with esophageal squamous cell carcinoma risk and gene-environment interactions in Eastern Chinese populations. SciRep. 2015; 5:8250-8261.
36. Zhu ML, Yu H, Shi TY, He J, Wang MY, Li QX, Sun MH, Jin L, Yang YJ, Wang JC, Xiang JQ, Wei QY. Polymorphisms in mTORC1 genes modulate risk of esophageal squamous cell carcinoma in eastern Chinese populations. J Thorac Oncol. 2013; 8:788-795.

37. Hidebrandt MA, Yang H, Hung MC, Izzo JG, Huang M, Lin J, Ajani JA, Wu X. Genetic variations in the PI3K/ PTEN/AKT/mTOR pathway are associated with clinical outcomes in esophageal cancer patients treated with chemoradiotherapy. J Clin Oncol. 2009; 27:857-871. 